The productivity $\mathrm{P}$, i.e. number of piglets weaned per sow and per year, estimated by progressive multiple regression from the variables, is expressed by :

$$
\mathrm{P}=8.8 \mathrm{I} 7+\mathrm{I} .735 x_{1}-0.204 x_{2}-0.092 x_{3}-0.09 \mathrm{I} x_{4}(\mathrm{R} \ldots 0.98 \mathrm{I})
$$

$x_{1}=$ mean prolificacy,

$x_{2}=$ losses from birth to weaning (p. Ioo),

$x_{3}=$ weaning-conception interval (days),

$x_{4}=$ weaning age (days).

Thus, the gain of one piglet weaned per sow and per year can be obtained in the following way :

- either by increasing the prolificacy by 0.58 piglet at birth

- or by reducing,

either the losses from birth to weaning by $4.9 \mathrm{p}$. Ioo

or the weaning-conception interval by 10.9 days

or the age at weaning by 10.9 days.

For one week gained at each reproductive cycle, the numerical productivity is improved by 0.64 piglet. The improvement of piglet production depends on a series of coherent measures and the possible margin of progress remains large in the French pig herds.

\title{
Effects of month of farrowing, litter order and genetic type of the mother on the components of sow productivity in French farms
}

\author{
C. IEGAULT, J. DAGORN* and D. TASTU \\ Station de Génétique quantitative et appliquée, I. N.R. A., C. N.R. Z., \\ 78350 Jouy en Josas \\ * Institut technique du Porc, \\ 149, rue de Bercy, \\ 75579 Paris Cedex 12
}

Data collected in lirench farms were analysed in order to estimate the effects of month of farrowing, litter order and genetic type of the female on the components of sow productivity.

In the first study, $17660 \mathrm{I}$ litters werc classified according to their month of birth (I 2 levels), Iitter order ( 7 levels) and genetic type of the sow (4 levels) and submitted to a least squares analysis. The greatest litter sizes at birth were observed in January $(0.26$ piglet more per litter than in July and August) ; Inversely, the greatest litter sizes at weaning corresponded to birth in June (o.34 piglet more per litter than in December). Weaning-conception interval was I I days longer when farrowing took place in June as compared to farrowing in Jecember. Moreover, this interval was 7 days longer in primiparous than in multiparous sows.

In the second study, 2 I I I litters were classified according to herd (88 levels), litter order (6 levels) and genetic type of the sow (Large White, Large White $\times$ Landrace, Landrace $\times$ Large White and Landrace) and submitted to the same analysis as previously. At least two genetic types 
were represented in each herd. Heterosis effect was estimated by the relative superiority of the average of the two reciprocal crosses relatively to the average of the parental breeds. The heterosis effect was : 3, 4, is and 6 p. Ioo respectively for litter size at birth, at weaning, weaning conception-interval and numerical productivity of the sow (number of piglets weaned/sow/year).

Differences between reciprocal crosses were low. The weaning-conception interval was almost independent of the litter size $(r=-0.03)$ and very slightly associated with lactation length $(r=-0.06)$.

\title{
Productivity of sows in France as afiected by housing eonditions, equipment of farrowing pens and age at weaning
}

\author{
A. Aumaitre, J. M. PEREZ and J. ChauveL* \\ Station de Recherches sur l'Élevage des Porcs, I. N. R. A., C. N. R. Z., \\ 78350 Jouy en Josas \\ * Institut technique du Pore, \\ 149, rue de Bercy, \\ 75579 Paris Cedex 12
}

Two series of data were used in this study : the first one concerned performance recordings of 247462 litters of piglets born between 1965 and 1973 in all regions of France and the second one proceeded from the results of the National computerized programme for analysis of on-the-farm sow records concerning performances of 217 I30 litters born between 1969 and 1974 .

Mean losses of piglets (2.13 piglets lost per litter between birth and weaning, calculated from I 35508 data) represent 19,8 p. Ioo of the total number of animals born (Io, 8 piglets/litter). These losses reach a maximum in badly heat conditioned farrowing houses (2.27 per litter in huts heated with lamps, 2.I 7 in farrowing houses without lamp heating and 2.03 in farrowing houses heated with lamps). Among all devices used for the internal arrangement of the pens, the farrowing rail appears to be the less favourable system (2.30 piglets lost) and that according to which the sows are blocked or attached, the most favourable one (2.03 piglets lost per litter). These results emphasize the importance of the efforts to be made with respect to internal arrangement and thermic protection of farrowing houses.

The mean age at weaning of the piglets has regressed from 6I days in 1965 to 38 days in 1973 , $i$. e. a mean reduction of 3.7 days per year. In addition, for the period I969-1974 taken as a whole, one fourth of the litters observed was weaned before $3 \mathrm{r}$ days, indicating a very marked trend towards very early weaning of piglets in the practice of French pig production. This trend is particularly clear in large herds (Ioo sows and more).

The interval between weaning and conception is generally abnormally long (22 days). This interval is excessively lengthened (45 days) in the case of too early weaning before ro days or too late weaning after the age of 50 days (I I p. Ioo of the sows are not fertilized 2 months after weaning). On the other hand, the percentage of fertilized animals is days after weaning varies little (68 p. roo on an average) for weanings between 16 and 45 days.

The age at weaning has a very small (but active) influence on the litter sist : thus, the mean number of weaned piglets increases with the age at weaning at the previous cycle (the number 